\title{
Children Born Small for Gestational Age: Do They Catch Up?
}

\author{
A. C. S. HOKKEN-K()ELEGA, M. A. J. DE RIDDER, R. J. LEM.MIN, H. DIN HARTOG, S. M. P. F. \\ DE MLINCK KEIZER-SCHRAMA, AND S. L. S. DROP \\ Department of Pediatrics, Division of lindocrinology, Sophia Children's Hospital/Erasmus University; \\ Rotterdam /A.C.S.H.-K., R.J.I., H.d.H., S.M.P.F.d.M.K.-S., S.L.S.D.I and Department of Epidemiology and \\ Biostatistics, Erasmus University Rotterdam [M.A.J.d.R.I. The Netherlands
}

\begin{abstract}
Postnatal growth of $72+(423$ premature, 301 full-tcrm) small for gestational age infants (SGA, birth length less than the third length percentile (P.3) for gestational agc) was studicd for the first $2 y$ of life. The study group consisted of all SGA infants who had been admitted over a period of $s y$ at the Departments of Neonatology of threc University Hospitals in The Netherlands with exclusion of infants with well defined causes for growth retardation, such as chromosomal disorders, syndromes, severe malformations, or complications during the neonatal period or later (nn. The aim of the study was to describe postnatal growth of SGA infants and to find predictive factors for catch-up growth $\geq \mathrm{P} 3$ during the first $2 \mathrm{y}$ of life. The majority (around $85 \%$ ) of the healthy SGA infants showed catch-up growth to a height $\geq \mathrm{P} 3$ during the first $2 y$ of life. The percentage of premature SGA infants with catch-up growth $\geq \mathrm{P} 3$ at $2 \mathrm{y}$ of age $(82.5 \%)$ was not significantly different from that of full-term SGA infants $(87.5 \%)$. Birth length SDS was more sensitive than birth weight
\end{abstract}

ABSTRACT
Children with IUGR comprise a heterogenous group of newborns (1). Infants may be born cither full-term or premature. IUGR may be sccondary to a chromosomal disorder. intrauterine infection, maternal disease, placental dysfunction, cigarette smoking, and multiple birth; however, in the majority of cases the etiology is not apparent.

It has been reported that full-term infants born SGA without an underlying disorder do show catch-up growth within the first years of life. However, the percentage of children who fail to show catch-up growth after birth is different in various studies ranging from 13 to $40 \%(2-5)$. This is mainly the result of various definitions of $\mathrm{SG} \wedge$ and different inclusion criteria of the studies. Commonly used definitions of SGA are: birth weight less than 10th or 5 th percentile for gestational age; birth weight less than 2 SD below the mean value for gestational

Received December 22, 194.4: accepted April 13, 1995

Manuscipt dedicated to Professur H.K.A. Visser in henor of his retirement

Correspondence and reprint requess: Dr. A. (. S. Hukken-Koclega, Department of Pediatrics, Division of Endocrinology. Sophia Children's Hospital. Dr. Molewaterplein (0). 3015 GJ Rolterdam, The Netherlands.

Supported hy Novo Nordisk A/S, Denmark.
SDS in predicting catch-up $\geq P 3$ in premature SGA infants. In contrast, birth weight SDS was the best predictor for catch-up $>$ P3 in full-tcrm SGA infants. Gestational age, multiple birth, and sex were not significantly associated with catch-up in height $\therefore$ P3. For children with a length still below P3 at 3 or 6 mo of age, the actual length SDS at that agc appeared positively associated with catch-up $\geq P$ P . In SGA premature infants there was also a positive association between the weight gain during the first $6 \mathrm{mo}$ and the catch-up growth $\geq P 3$. S(iA children with short stature (height $<\mathrm{P} 3$ ) at $2 \mathrm{y}$ of age need further investigation. (Pediatr Res 38: 267-271, 1995)
Abbreviations
IUGR, intrauterine growth retardation
S(iA, small for gestational age
SISS, standard deviation score for chronologic age
P3, third length percentile $(=\cdot 1.88$ SDS)

age; birth weight less than $2500 \mathrm{~g}$ and gestational age greater than or equal to $37 \mathrm{wk}(2,3)$. However, short stature usually being defined as a height below the 3 rd or 5 th height percentile of a reference population, it seems more adequate to define SGA in terms of short length at birth, i.e'. a birth length below the 3 rd or 5 th percentile for gestational age. Only very limited research has been done on the postnatal growth of premature infants born SGA (6).

We, therefore, evaluated the postnatil growth of 724 SGA infants, who were born prematurely or full-term with a birth length less than the P3 for gestational age. The aim of the study was to describe postnatal growth of SGA infants and to find predictive factors for catch-up growth 10 a height at or above the P3 during the first 2 y of life

\section{METHODS}

From January 1980 to January 1989. 858 SGA infants, who were defined by a short birth length of more than $1.88 \mathrm{SD}$ below the expected mean for gestational age $(<\mathrm{P} 3)(7)$, were admitted at the Departments of Neonatology of three Univer- 
sity Hospitals in The Netherlands [Sophia Children's Hospital Rotterdam (center A), Free University of Amsterdam (center B), and University of Leiden (center C)]. We evaluated the growth data of these infants retrospectively, with the exclusion of 134 children. Thirty-two infants had died within $1 \mathrm{y}$ after birth, 22 children were lost to follow-up, and one parent refused to have data of his child included. In addition, we excluded 79 infants with major congenital anomalies or chromosomal defects at birth or medical complications/chronic disease during infancy. Hence, 724 healthy SGA infants (344 boys and 380 girls) were included in our study. The study group consisted of 423 premature and 301 full-term SGA infants. The study was approved by the Ethics Committees of the participating hospitals. Written informed consent was obtained from the parents.

Gestational age was determined from mother's dates, in case of doubt confirmed by ultrasound before $20 \mathrm{wk}$ and/or Dubowitz score at birth (8), rounded off to full weeks. Infants born before 37 wk were designated premature; those born between 37 and 43 wk were designated full-term. Birth length was measured in 585 and birth weight in all 724 infants. The birth length of 139 infants was considered to be $1.88 \mathrm{SD}$ below the expected mean for gestational age on the basis of several length measurements being below -1.88 SDS $(<\mathrm{P} 3)$ during the first weeks after birth.

All children were examined at birth and regularly throughout the neonatal period. Discharge from follow-up occurred only when the child had achieved a height above the P3, whereas children with a height below P3 at 2 y of age were followed until at least the age of 5 .

Weight and length at birth and during follow-up were measured by experienced nurses, using a standard measuring board or a Harpenden stadiometer. The chronologic age was corrected for gestational age, that is, for the number of weeks different from the expected $40.0 \mathrm{wk}$. Length and weight at birth were expressed in SDS or length percentile after correction for gestational age (7). Similarly, all postnatal growth data were expressed in SDS or height percentile (9) up to $2 \mathrm{y}$ of age (gestational-age-corrected age $\left(\mathrm{CA}_{c}\right)$ ). The growth analysis included growth data at $3,6,12$, and 24 mo of $\mathrm{CA}_{c}$. Not all children being measured at exactly these ages, but shortly before or after, we computed the percentiles from the growth curves by linear interpolation.

Two-sample $t$ test was used to assess differences between two groups. To study the influence of a number of variables on the capacity to catch-up to a height at or above P3 at 2 y of age ("catch-up growth $\geq \mathrm{P} 3$ "), we started with carrying out an univariate logistic regression analysis for each variable separately. To determine the influence on catch-up growth $\geq \mathrm{P} 3$ of several variables simultaneously, we then carried out multiple logistic regression analyses. A stepwise, forward procedure was used to carry out three analyses. In the first analysis the variables known at birth were used, such as sex $(1=$ male; 0 $=$ female), gestational age (weeks), birth weight SDS and birth length SDS, and multiple births $(1=$ yes; $0=$ no). Next, analyses were performed at 3 and 6 mo after birth for children who had not yet reached the P3 at that time. These analyses involved a stepwise selection on the variables known at birth and postnatal variables (i.e. the length and weight SDS at 3 and $6 \mathrm{mo}$, and the change in length SDS and weight SDS during 3 and 6 mo after birth, respectively). One of the centers (B) measured birth length in $97.6 \%$ (249) of the 255 SGA infants, but birth length was not available for 133 SGA infants (28.4\%) of the other centers. For that reason we started our search for predicting variables in the group of 249 infants with complete birth data who had been admitted at center B. Their mean (SD) gestational age was 35.0 (3.4) and birth weight SDS -2.4 (0.9), which was comparable with the mean (SD) values of the SGA infants of the other centers, being 35.4 (3.2) and -2.8 (0.8), respectively. We consecutively searched for predicting variables for the premature and full-term SGA infants of all three centers, using birth weight SDS instead of birth length SDS.

\section{RESULTS}

Clinical data of 724 SGA infants are summarized in Table 1. Mean birth weight SDS as well as birth length SDS were significantly lower for premature than for full-term SGA infants $(p<0.0001)$.

\section{Postnatal Growth}

Figure 1 presents the percentages of premature and full-term SGA infants with catch-up growth $\geqq \mathrm{P} 3$ at various time points from birth up to $2 \mathrm{y}$ of age. Figure 2 shows the percentages of premature and full-term SGA infants with catch-up growth $\geq \mathrm{P} 3$ for the various subgroups of birth length SDS.

Spontaneous catch-up growth $\geq \mathrm{P} 3$ occurred in $53 \%$ ( $n=$ $381)$ of all SGA infants during the first $6 \mathrm{mo}$, in $72 \%(n=518)$ before the age of $1 \mathrm{y}$ and in $85 \%$ during the first $2 \mathrm{y}$ after birth. The remaining 15\% (111 children) formed the no-catch-up group with a height still below P3 at 2 y of age. During the first year catch-up growth was more frequently seen in girls $(75 \%)$ than in boys $(68 \%)(P=0.03)$. At $2 \mathrm{y}$ of age, however, this sex difference had disappeared.

Premature SGA infants $(n=423)$. Forty percent of the premature SGA infants $(n=167)$ had a catch-up growth $\geq \mathrm{P} 3$ during the first $6 \mathrm{mo}$ and $65 \%$ of them $(n=275)$ before the age of $1 \mathrm{y}$. Spontaneous catch-up growth $\geq \mathrm{P} 3$ during the first $2 \mathrm{y}$ after birth occurred in $82.5 \%$ of the premature SGA infants. The remaining $17.5 \%(n=74)$ had a height still below P3 at $2 y$ of age. Eight of them showed catch-up growth to a height at or just above P3 after $2 \mathrm{y}$ of age. Their birth length SDS had

Table 1. Clinical data of 724 SGA infants

\begin{tabular}{llll}
\hline & \multicolumn{3}{c}{ Small for gestational age } \\
\cline { 2 - 4 } \multicolumn{1}{c}{ Clinical data } & Premature & Full-term & Total \\
\hline Total patients & 423 & 301 & 724 \\
Male $(n)$ & 206 & 138 & 344 \\
Female $(n)$ & 217 & 163 & 380 \\
Gestational age $(w k)$ & $33.0(2.1)$ & $38.6(1.3)$ & $35.3(3.3)$ \\
Birth weight SDS & $-2.75(0.9)^{*}$ & $-2.47(0.7)$ & $-2.63(0.8)$ \\
Birth length SDS & $-3.43(1.2)^{*}$ & $-2.87(0.9)$ & $-3.18(1.1)$ \\
Multiple birth $(n)$ & 54 & 41 & 95 \\
Follow-up $(y)$ & $3.5(2.3)$ & $3.5(2.5)$ & $3.5(2.4)$ \\
\hline
\end{tabular}

Data expressed as mean (SD) or number.

$*=\mathrm{P}<0.0001$ compared to full-term infants. 


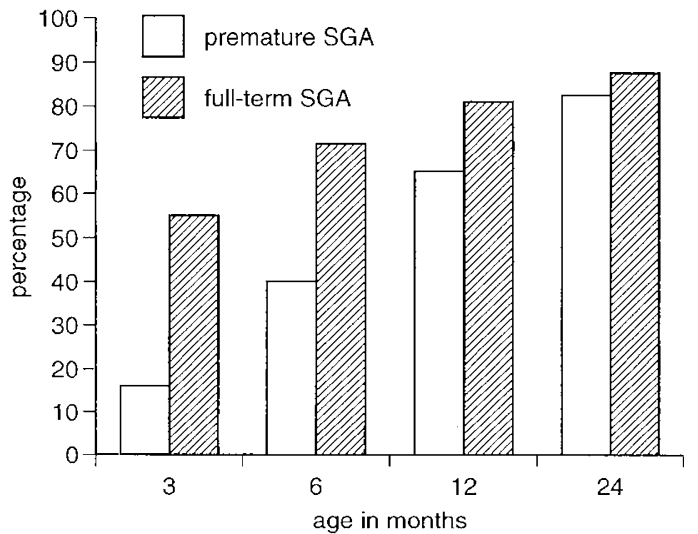

Figure 1. Percentage of SGA infants with postnatal catch-up growth to a height $\geq \mathrm{P} 3$ at various ages. Data are given for premature (white bars) and full-term (hatched bars) infants of the total study group.

been very low, i.e. $<-3.5$ SDS. At the age of $2 \mathrm{y}$ these children were still "catching-up." Catch-up growth $\geq \mathrm{P} 3$ at $2 \mathrm{y}$ of age occurred in $82 \%$ of the 367 premature SGA infants who were born with a birth weight and a birth length $<\mathrm{P} 3$ and in $89 \%$ of the 56 premature infants born with a birth length $<$ P3 but a birth weight just above the P3, the difference not being significant.

Figure 2 shows that premature SGA infants with very severe intrauterine growth retardation (birth length $<-3.5$ SDS) had the highest percentage (36\%) of no catch-up growth $\geq \mathrm{P} 3$.

Full-term SGA infants $(n=301)$. Seventy-one percent of the full-term SGA infants $(n=214)$ had a catch-up growth $\geq \mathrm{P} 3$ during the first 6 mo of life and $81 \%(n=243)$ before the age of $1 \mathrm{y}$. Eighty-seven and one-half percent of the SGA full-term infants showed spontaneous catch-up growth $\geq \mathrm{P} 3$ during the first $2 \mathrm{y}$ after birth. The height of 37 children $(12.5 \%)$ remained below P3 at 2 y of age. Catch-up growth $\geq \mathrm{P} 3$ at 2 y of age occurred in $86 \%$ of the 253 full-term SGA infants who were born with a birth weight and a birth length $<$ P3 and in $98 \%$ of the 48 full-term infants born with a birth length $<$ P3 but a birth weight above the P3, the difference being significant $(p=0.02)$.

Full-term SGA infants with a birth length $<-2.5$ SDS had a higher percentage of no catch-up growth $\geq \mathrm{P} 3(18-21 \%)$ than those with relatively less intrauterine growth retardation $(4 \%)$ (Fig. 2).

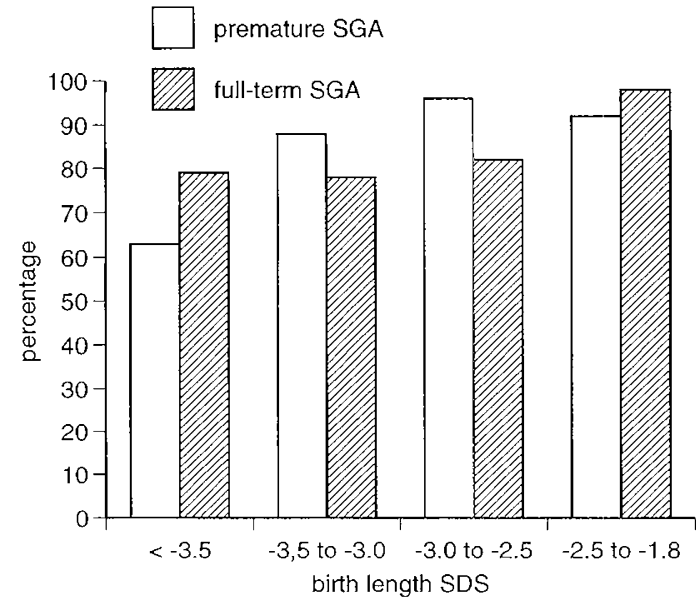

Figure 2. Percentage of SGA infants with postnatal catch-up growth to a height $\geq \mathrm{P} 3$ for various subgroups of birth length SDS. Data are given for premature (white bars) and full-term (hatched bars) infants of center $\mathrm{B}$.

\section{Predictors for Catch-Up Growth $\geq P 3$}

Premature SGA infants. Univariate analysis of the growth data of 149 SGA premature infants from center B revealed a significant positive association between catch-up growth at $2 \mathrm{y}$ of age and birth length SDS $(p<0.0001)$ as well as birth weight SDS $(p=0.04)$. However, when both variables were entered in a stepwise logistic regression analysis it appeared that birth length SDS was superior $(p=0.0002)$ to birth weight $\operatorname{SDS}(p=0.72)$ in its association with catch-up growth (Table 2). Gestational age, multiple birth, and sex were not significantly associated with catch-up growth $\geq \mathrm{P} 3$ at $2 \mathrm{y}$. The stepwise logistic regression analyses which were performed at 3 and 6 mo of age for children who had not yet reached the P3 at that time, resulted in models containing at 3 mo of age the actual length SDS and at 6 mo of age the actual length SDS as well as the increase in weight SDS over the first 6 mo of life.

Because birth length was not measured in 139 SGA premature infants of the other two centers, we decided to use birth weight SDS instead of birth length SDS in the stepwise logistic analyses performed on the data of the total group of SGA premature infants. The predictors for catch-up growth, the odds ratios and the $95 \%$ confidence limits for catch-up growth $\geq \mathrm{P} 3$ at $2 \mathrm{y}$ of age for the total group of premature SGA infants at

Table 2. Variables associated with catch-up growth to a height $\geq P 3$ at 2 y of age in children born SGA

\begin{tabular}{|c|c|c|c|c|c|c|c|c|}
\hline \multirow[b]{2}{*}{ Age } & \multicolumn{4}{|c|}{ Premature SGA } & \multicolumn{4}{|c|}{ Full-term SGA } \\
\hline & Variables & OR & $95 \% \mathrm{CI}$ & $p$ & Variables & OR & $95 \% \mathrm{CI}$ & $p$ \\
\hline \multicolumn{9}{|l|}{ At birth } \\
\hline Center $\mathrm{B} \dagger$ & Birth length SDS & 2.43 & $1.49-3.96$ & 0.0002 & & & & \\
\hline \multirow[t]{2}{*}{ Total group* } & Gestational age (wk) & 1.24 & $1.09-1.41$ & 0.001 & Birth weight SDS & 2.74 & $1.70-4.41$ & $<0.0001$ \\
\hline & Birth weight SDS & 2.23 & $1.59-3.13$ & $<0.0001$ & & & & \\
\hline \multicolumn{9}{|l|}{ At $13 \mathrm{wk}$} \\
\hline Total group** (when length still < P3) & Length SDS & 2.62 & $1.90-3.62$ & $<0.0001$ & Weight SDS & 1.97 & $1.27-3.08$ & 0.003 \\
\hline \multicolumn{9}{|l|}{ At $26 w k$} \\
\hline \multirow{2}{*}{ Total group*** (when length still < P3) } & Length SDS & 2.76 & $1.72-4.42$ & $<0.0001$ & Length SDS & 2.63 & $1.00-7.00$ & 0.03 \\
\hline & $\begin{array}{c}\Delta \text { Weight SDS } \\
(0-26 \mathrm{wk})\end{array}$ & 2.28 & $1.29-4.02$ & 0.004 & & & & \\
\hline
\end{tabular}

Baseline odds for premature SGA: $\uparrow 96.35, * 0.04, * * 120.51, * * * 38.57$. Baseline odds for full-term SGA: * 103.20,**10.32,***12.10. OR odds ratio $(>1.0$ means increased risk); CI, confidence interval. 
each of the specified time points are given in Table 2. At birth the birth weight SDS was positively and the gestational age was negatively associated with catch-up growth. For children with a length still below P3 at 3 mo of age, the actual length SDS at 3 mo was positively associated with catch-up $\geq P 3$. For those with a length below P3 at 6 mo of age, it appeared that the actual length SDS at $6 \mathrm{mo}$ as well as the increase in weight SDS during the first 6 mo of life were positively associated with catch-up growth.

\section{Full-term SGA Infants}

Univariate analysis of the complete growth data of 100 full-term SGA infants from center $B$ revealed a significant positive association between catch-up growth at $2 \mathrm{y}$ of age and birth weight $\operatorname{SDS}(p=0.0001)$ and birth length $\operatorname{SDS}(p=$ 0.002 ). When both variables were entered in a stepwise logistic regression analysis it appeared that birth weight SDS was superior $(p=0.002)$ to birth length $\operatorname{SDS}(p=0.94)$ in its association with catch-up growth. Gestational age, multiple birth, and sex did not significantly influence catch-up growth at $2 \mathrm{y}$. The stepwise logistic regression analyses which were performed at 3 and 6 mo of age for children who had not yet reached the $\mathrm{P} 3$ at that time, resulted in models containing birthweight SDS at 3 and 6 mo of age.

Stepwise logistic regression using data of all 301 full-term SGA infants indicated birth weight SDS as the best predictive factor for catch-up growth at birth, actual weight SDS at 3 mo of age and actual length SDS at 6 mo of age for those still being below the P3 at these time points (Table 2).

\section{DISCUSSION}

Our study revealed that $85 \%$ of SGA infants who were born with a birth length below the third percentile (P3), i.e. more than -1.88 SDS below the mean for gestational age, will show spontaneous catch-up growth to a height $\geq \mathrm{P} 3$ during the first $2 \mathrm{y}$ of life. During the first year the percentage of infants showing catch-up growth $\geq \mathrm{P} 3$ was greater for full-term than for premature SGA infants. At $2 \mathrm{y}$ of age, however, there was no significant difference in percentage of catch-up growth $\geq \mathrm{P} 3$ between premature $(82.5 \%)$ and full-term $(87.5 \%)$ SGA infants. Thus, $17.5 \%$ of the premature and $12.5 \%$ of the full-term SGA infants failed to show full catch-up growth $\geq \mathrm{P} 3$.

It has previously been reported that $26-40 \%$ of SGA children remain short $(2-5)$. This wide variation might very well be the result of the various definitions of SGA and different inclusion criteria used in the various studies. There are many definitions of SGA. Most involve exclusively birth weight: birth weight less than 10th or 5th percentile for gestational age; birth weight less than 2 SD below the mean value for gestational age; birth weight less than $2500 \mathrm{~g}$ and gestational age greater than or equal to $37 \mathrm{wk}$. Short stature in later life, however, is usually defined as a height, not as weight below the 3 rd or 5 th height percentile of a reference population, whereas catch-up growth is usually defined as accelerated growth up to a height above the P2.5, P3, or P5 (2-6). For these reasons, it seems more logical to define SGA in terms of short length at birth. We, therefore, defined SGA on the basis of a birth length below the 3 rd percentile, i.e. a birth length below -1.88 SDS.

Our findings correspond very well with the results of a recent study reporting $2-y$ and final height data in a cohort of 111 uncomplicated full-term SGA infants with a short birth length below -2 SDS (4). Of these, $87 \%$ were within the normal range for length at $2 \mathrm{y}$ of age, whereas $13 \% \mathrm{did}$ not fully catch-up before $2 y$ of age nor at a later age up to final height. Their results together with our findings indicate that catch-up growth after $2 \mathrm{y}$ of age is very unlikely to occur in full-term SGA infants. Most of the full-term SGA infants have more or less finalized their catch-up growth before $1 \mathrm{y}$ of age. Our results show that $60 \%$ of the full-term SGA infants who failed to catch up $\geq \mathrm{P} 3$ before 6 mo of age will not attain full catch-up growth $\geq \mathrm{P} 3$ at $2 \mathrm{y}$ of age.

Our study is the first one to describe postnatal growth in a large group of uncomplicated premature infants who were born with a birth length $<$ P3 for gestational age. Our results show that most premature SGA infants had a gradual improvement of height during the 2-y period. The mean birth length SDS of the premature infants was significantly less than that of the full-term infants, but at $2 \mathrm{y}$ of age there was no significant difference in percentage of catch-up growth $\geq \mathrm{P} 3$ between premature and full-term SGA infants, which makes the substantial catch-up growth in the SGA premature infants even more striking. Our findings showed that premature SGA infants with very severe intrauterine growth retardation (birth length $<-3.5$ SDS) had the highest percentage (36\%) of no catch-up growth $\geq \mathrm{P} 3$ at $2 \mathrm{y}$ of age. However, this percentage might be relatively high due to some premature SGA infants ( $n$ $=8$ ) who failed to catch up $\geq \mathrm{P} 3$ during 2 y of age, but who reached a height at or just above the P3 between 2 and 4 y of age. They were born after severe IUGR with a birth length $<$ $-3.5 \mathrm{SDS}$, showed a steady improvement in postnatal height, and were the only ones still "catching-up" at 2 y of age.

Although most SGA infants show catch-up growth during the first years of life, those who do not constitute $20-25 \%$ of children who are short in later life (10). Some studies have indicated that $25-60 \%$ of the children with short stature related to IUGR have a subnormal growth hormone secretion (11-13). Consequently, we feel that full-term SGA children without catch-up growth $\geq \mathrm{P} 3$ at $2 \mathrm{y}$ of age need further investigation in order to exclude treatable conditions such as hypothyroidism, growth hormone deficiency, and celiac disease. A similar approach should be considered for premature SGA children who failed to reach a height at or above the P3 at $2 \mathrm{y}$ of age and who lack any sign of catch-up growth during the second year after birth. Premature SGA infants who are still "catching-up" at $2 \mathrm{y}$ of age should be regularly followed at the clinics until they grow along a certain growth percentile $\geq \mathrm{P} 3$ for at least $1 \mathrm{y}$.

The logistic regression analysis on the complete growth data of infants, who had been admitted at one of the centers, revealed that birth length SDS was a significant predictor for catch-up growth $\geq \mathrm{P} 3$ at $2 \mathrm{y}$ of age in premature SGA infants, being superior to birth weight SDS in its association with catch-up growth. Unfortunately, birth length was not always measured in the other centers from 1983 onward, particularly 
not so in premature infants with a low gestational age and severe intrauterine growth retardation. This new routine appeared following suggestions that length measurement of newborns might induce hip dysplasia. Our findings, however, underline that maximal effort should be made to measure the length at birth or at least within the first week(s) after birth, particularly in premature SGA infants.

When birth length SDS was not entered in the logistic regression analysis due to incompleteness of data, it appeared that birth weight SDS was positively and gestational age was negatively associated with catch-up $\geq \mathrm{P} 3$ in premature SGA infants. For infants with a length still below P3 at 3 mo of age, the actual length SDS was positively associated with catch-up $\geq$ P3. For those with a length below P3 at 6 mo of age, it appeared that both the actual length SDS at that time and the increase in weight SDS during the first 6 mo of life were positively associated with catch-up $\geq \mathrm{P} 3$. These findings might suggest that efforts should be made to optimize weight gain in premature SGA infants.

The logistic regression analyses on data of full-term SGA infants revealed that at birth the birth weight SDS was the best predictor for catch-up growth at $2 \mathrm{y}$ of age, even superior to the influence of birth length SDS. Thus, although birth length measurements occurred more often in full-term than in premature SGA infants, it seems less important to measure birth length in full-term infants. For full-term infants with a length still below P3 at three months of age, the length and weight SDS at that age were positively associated with catch-up $\geq \mathrm{P} 3$, but weight SDS more so than length SDS. For those with a length still below P3 at 6 mo of age, it appeared that the length SDS at that time was positively associated with catch-up $\geq \mathrm{P} 3$.

In conclusion, our study shows that the majority $(85 \%)$ of healthy SGA infants, defined by a birth length below P3 for gestational age, will show catch-up growth to a height at or above P3 during the first $2 \mathrm{y}$ of life. The percentage of SGA infants with catch-up $\geq \mathrm{P} 3$ at 2 y is not significantly different for SGA infants born prematurely or full-term, but premature infants need a longer period for their catch-up $\geq P$ P. Birth length SDS is more sensitive than birth weight SDS in predicting catch-up $\geq \mathrm{P} 3$ in premature, but not in full-term SGA infants. Birth weight SDS is a significant predictor for catch-up growth for all SGA infants. For children with a length still below P3 at 3 and 6 mo of age, the influence of birth data is overtaken by the actual length SDS which appears positively associated with catch-up $\geq \mathrm{P} 3$. Optimization of weight gain in premature SGA infants might have a positive influence on catch-up growth. Our study indicates that SGA infants born either prematurely or at full-term should be measured regularly by the same experienced persons, at least until they have reached a height above the P3. SGA children with a height $<\mathrm{P} 3$ at $2 \mathrm{y}$ of age and no signs of catch-up growth during the previous 6 mo need further investigation.

Acknowledgments. The authors thank the pediatric neonatologists of the three participating centers (Sophia Children's Hospital, Erasmus University Rotterdam, and the Free University of Amsterdam and the University of Leiden) for their cooperation.

\section{REFERENCES}

1. Wennergren M, Wennergren G, Vilbergsson G 1988 Obstretric characteristics and neonatal performance in a four-year small for gestational age population. Obstet Gynecol 72:615-620

2. Fitzhardinge PM, Steven EM 1972 The small-for-date infant. I. Later growth patterns. Pediatrics 49: 671-681

3. Albertsson-Wikland $\mathrm{K}$, Wennergren $\mathrm{G}$, Wennergren $\mathrm{M}$, Vilbergsson $\mathrm{G}$, Rosberg $S$ 1993 Longitudinal follow-up of growth in children born small for gestational age. Acta Paediatr 82:438-443

4. Albertsson-Wikland K, Karlberg J 1994 Natural growth in children born small for gestational age with and without catch-up growth. Acta Paediatr Suppl 399:64-70

5. Tenovuo A, Kero P, Piekkala P, Korvenranta H, Sillanpaa, Erkkola R 1987 Growth of 519 small for gestational age infants during the first two years of life. Acta Paediatr Scand 76:636-646

6. Fitzhardinge PM, Inwood S 1989 Long-term growth in small-for-date children. Acta Paediatr Scand Suppl 349:27-33

7. Usher R, McLean F 1969 Intrauterine growth of live-born caucasian infants at sea level: Standards obtained from measurements in 7 dimensions of infants born between 25 and 44 weeks of gestation. J Pediatr 74:901-910

8. Dubowitz LMS, Dubowitz V, Goldberg C 1970 Clinical assessment of gestational age in the newborn infant. Pediatrics 77:1-10

9. Roede MJ, Van Wieringen JC 1985 Growth diagrams 1980 Netherlands third nation-wide biometric survey. Tijdschr Soc Gezondheidszorg 63(suppl):1-34

10. Karlberg J, Albertsson-Wikland K 1993 Spontaneous growth and final height in SGA infants. Pediatr Res 33:S53

11. Stanhope R, Ackland FM, Hamill G, Claytin J, Jones J, Preece MA 1989 Physiological GH secretion and responses to $\mathrm{GH}$ treatment in children with short stature and IUGR. Acta Paediatr Scand 349:47-51

12. Albertsson-Wikland K $1989 \mathrm{GH}$ secretion and GH treatment in children with IUGR. Acta Paediatr Scand 349:35-41

13. De Waal WJ, Hokken-Koelega ACS, Stijnen Th, De Muinck Keizer-Schrama SMPF, Drop SLS 1994 Endogenous and stimulated GH secretion, urinary GH excretion, and plasma IGF-I and IGF-II levels in prepubertal children with short stature after intrauterine growth retardation. Clin Endocrinol 41:621-630 